\title{
CONTROLE DA ANTRACNOSE NA PÓS-COLHEITA DE MANGA 'UBÁ' COM O USO DE PRODUTOS ALTERNATIVOS
}

\author{
LORENA MOREIRA CARVALHO LEMOS ${ }^{2}$, PAULO HENRIQUE COUTINHO ${ }^{3}$, \\ LUIZ CARLOS CHAMHUM SALOMÃO ${ }^{4}$, DALMO LOPES DE SIQUEIRA ${ }^{4}$, PAULO ROBERTO CECON $^{5}$
}

RESUMO - Foi avaliada a eficácia de produtos alternativos aos agroquímicos no controle da antracnose na póscolheita de mangas 'Ubá'. Frutos fisiologicamente maduros foram pulverizados até o completo molhamento, com suspensão de conídios de Colletotrichum gloeosporioides, na concentração de 2,5 x $10^{5}$ conídios $/ \mathrm{mL}$. Após a secagem ao ar, foram pulverizados com água destilada (testemunha), tween 20 ( $8 \mathrm{~mL} / \mathrm{L}$ de solução), Prochloraz $(1,10 \mathrm{~mL}$ de Sportak $450 \mathrm{EC} / \mathrm{L}$ de solução), óleo de alho $(10 \mathrm{~mL} / \mathrm{L}+8 \mathrm{~mL} / \mathrm{L}$ de tween 20$)$, óleo de amêndoa de Acrocomia aculeata + leite em pó instantâneo (LPI) $(25 \mathrm{~mL} / \mathrm{L}+10 \mathrm{~g} \mathrm{LPI} / \mathrm{L})$, óleo de amêndoa de A. aculeata + tween $(25 \mathrm{~mL} / \mathrm{L}+8 \mathrm{~mL} / \mathrm{L}$ de tween 20$)$, biofertilizante agro-mos ${ }^{\circledR}(100 \mu \mathrm{L} / \mathrm{L})$, óleo de neen $(10 \mathrm{~mL} / \mathrm{L}+8 \mathrm{~mL} / \mathrm{L}$ de tween 20$)$, quitosana $(10 \mathrm{~mL} / \mathrm{L}+8 \mathrm{~mL} / \mathrm{L}$ de tween 20$)$ e biomassa cítrica $(10 \mathrm{~mL} / \mathrm{L}+8 \mathrm{~mL} / \mathrm{L}$ tween 20$) . \mathrm{O}$ solvente utilizado foi água destilada. Avaliaram-se o período de incubação, o período latente, a perda de massa fresca, a produção de $\mathrm{CO}_{2}$ e, diariamente, a severidade e incidência da doença. Os períodos mais curtos de incubação da doença foram observados nos frutos tratados com óleo de neen, água + tween e biomassa cítrica, com aproximadamente cinco dias. O óleo de amêndoa de A. aculeata + LPI e agro-mos ${ }^{\circledR}$ foram os produtos que mais retardaram o aparecimento dos sintomas, impondo à doença o período de incubação de nove dias após a inoculação do patógeno. Quanto à severidade, o óleo de amêndoa de macaúba + LPI e o Prochloraz foram os mais eficientes em conter o crescimento do patógeno até o oitavo dia após a inoculação, sendo que, logo depois, os frutos tratados com óleo de amêndoa de $A$. aculeata + LPI se igualaram àqueles tratados com a maioria dos demais produtos. Os frutos tratados com óleo de amêndoa de $A$. aculeata + LPI e óleo de amêndoa de $A$. aculeata + tween manifestaram as estruturas do patógeno apenas após 13 e 14 dias de avaliação, respectivamente. As maiores perdas de massa foram observadas nos frutos tratados com óleo de alho e biomassa cítrica, com $8,31 \%$ e $8,44 \%$, respectivamente, no dia 14. Quanto à produção de $\mathrm{CO}_{2}$, o óleo de amêndoa de A. aculeata + LPI e óleo de amêndoa de $A$. aculeata + tween mantiveram a taxa respiratória crescente, sendo que, no dia 12 ocorreu um leve aumento na respiração. Dessa forma, conclui-se que, além do Prochloraz, o óleo de amêndoa de A. aculeata + LPI e óleo de amêndoa de A. aculeata + tween têm bom potencial para controle da antracnose em manga 'Ubá'.

Termos para Indexação: Manejo de doença, óleos vegetais, conservação pós-colheita.

\section{CONTROL OF ANTHRACNOSE IN THE POST-HARVEST OF 'UBÁ' MANGO WITH THE USE OF ALTERNATIVE PRODUCTS}

\begin{abstract}
This study has assessed the effectiveness of alternative products to agrochemicals for the control of anthracnose in the post-harvest of 'Ubá' mango. Physiologically mature fruit were sprayed until complete wetting with spore suspension of Colletotrichum gloeosporioides in $2.5 \times 10^{5}$ conidia/mL concentration. After air drying, the following were sprayed with distilled water (control), tween $20(8 \mathrm{~mL} / \mathrm{L}$ of solution), Prochloraz (1.10 mL Sportak $450 \mathrm{EC} / \mathrm{L}$ of solution), garlic oil $(10 \mathrm{~mL} / \mathrm{L}+8 \mathrm{~mL} / \mathrm{L}$ of tween 20$)$, Acrocomia aculeata almond oil + instant milk powder (IMP) $(25 \mathrm{~mL} / \mathrm{L}+10 \mathrm{~g} \mathrm{IMP} / \mathrm{L})$, A. aculeata almond oil + tween $(25 \mathrm{~mL} / \mathrm{L}+8 \mathrm{~mL} / \mathrm{L}$ of tween 20$)$, agro-mos ${ }^{\circledR}$ biofertilizer $(100 \mu \mathrm{L} / \mathrm{L})$, neem oil $(10 \mathrm{~mL} / \mathrm{L}+8 \mathrm{~mL} / \mathrm{L}$ of tween 20$)$, chitosan $(10 \mathrm{~mL} / \mathrm{L}+$ $8 \mathrm{~mL} / \mathrm{L}$ of tween 20$)$ and citric biomass $(10 \mathrm{~mL} / \mathrm{L}+8 \mathrm{~mL} / \mathrm{L}$ of tween 20$)$. The solvent used was distilled water. Incubation period, latent period, fresh weight loss and production of $\mathrm{CO}_{2}$ were assessed along with daily severity and incidence of the disease. Shorter incubation periods of the disease were noted in fruit treated with neem oil, water + tween and citric biomass, with approximately five days. A. aculeata almond oil + IMP and agro-mos ${ }^{\circledR}$ were the ones that most delayed the onset of symptoms, resulting in an incubation period of nine days after pathogen inoculation. Regarding severity, A. aculeata almond oil + IMP and Prochloraz were the most efficient in hindering the growth of the pathogen at 8 days after inoculation, but soon fruit treated with $A$. aculeata almond oil + IMP equaled those treated with the other products. Fruit treated with $A$. aculeata almond oil + IMP and A. aculeata almond oil + tween expressed the structures of the pathogen only at 13 and 14 evaluation days, respectively. The largest mass losses were found for fruit treated with garlic oil and citric biomass, with $8.31 \%$ and $8.44 \%$ respectively at 14 days. As for the production of $\mathrm{CO}_{2}$, A. aculeata almond oil + IMP and A. aculeata almond oil + tween kept increasing respiratory rate, where only at 12 days there was a slight respiratory increase. Thus, we may conclude that in addition to Prochloraz, A. aculeata almond oil + IMP and A. aculeata almond oil + tween have good potential for the control of anthracnose in 'Ubá' mango.
\end{abstract}

Index terms: Disease management, vegetable oils, post-harvest storage.

\footnotetext{
${ }^{1}$ (Trabalho 018-13).Recebido em: 03-01-2013. Aceito para publicação em: 28-10-2013.

${ }^{2}$ Eng. Agr., M. Sc., Doutoranda do Dept ${ }^{\circ}$. de Fitotecnia (Bolsista CNPq), UFV/Viçosa-MG. E-mail: lorenamcarvalho@yahoo.com.br ${ }^{3}$ Eng. Agr., Mestre. Dept ${ }^{\circ}$. de Fitotecnia, UFV/Viçosa-MG. E-mail: coutinhoph@gmail.com

${ }^{4}$ Eng. Agr., Doutor. Dept ${ }^{\circ}$. de Fitotecnia, UFV/Viçosa-MG. E-mails: siqueira@ufv.br; 1salomao@ufv.br

${ }^{5}$ Eng. Agr., Doutor. Dept ${ }^{\circ}$. de Estatística, UFV/Viçosa-MG.E-mail: cecon@ufv.br
} 


\section{INTRODUÇÃO}

A aparência da manga é o fator mais importante do sucesso em sua comercialização, sendo os defeitos na casca pouco tolerados. A casca deve ser perfeita até chegar ao consumidor final, o que constitui um grande desafio, já que ela é frágil e, em lenticelas, costumam abrigar-se os esporos de Colletotrichum gloeosporioides Penz, agente causal da antracnose (BAGSHAW, 1989).

Na Zona da Mata Mineira, encontra-se com grande destaque a mangueira 'Ubá', que cresce espontaneamente em praticamente todos os municípios da região. Seus frutos são utilizados principalmente no processamento industrial, no entanto têm grande aceitação para o consumo in natura.

$\mathrm{O}$ tratamento químico tem sido o método mais utilizado para o controle do agente da antracnose em manga. No entanto, os fungicidas que são amplamente utilizados devido à sua alta capacidade sistêmica contra grande número de patógenos, possuem várias restrições de uso, dentre elas selecionar isolados resistentes em função de seu uso contínuo.

A ênfase em proteção de frutos pós-colheita contra podridões tem sido desviada do uso de produtos químicos para técnicas alternativas de controle, que garantam a segurança do produto e que não coloquem em risco a saúde dos consumidores (CAMILI et al., 2007).

Inúmeros trabalhos mostram a eficiência de extratos e óleos essenciais obtidos a partir de diversas espécies botânicas no controle de fitopatógenos através da inibição do crescimento micelial, indução da lise e evacuação do citoplasma (FIORI et al., 2000).

Produtos como o neen (Azadiractha indica A. Juss) (MOSSINI; KEMMELMEIER, 2005), cravoda-índia (Caryophillus aromaticus L.) (ROZWALKA et al., 2008), quitosana (BAUTISTA-BAÑOS et al., 2006), Agro-mos ${ }^{\circledR}$ (mananoligossacarídeo fosforilado) (ROSA et al., 2008), óleo de amêndoa de macaúba (Acrocomia aculeata (Jacq.) Lood. ex Mart.) (LIMA et al., 2008) e biomassa cítrica (ABREU et al., 2008) têm sido testados com sucesso no controle de várias podridões em plantas.

A crescente preocupação com o conceito de qualidade mercadológica e com a preservação do ambiente tem aumentado a procura por frutas saudáveis e sem resíduos de agroquímicos (ROZWALKA et al., 2008; NOGUEIRA et al., 2011). O presente trabalho objetivou avaliar o efeito de produtos alternativos aos agroquímicos no controle da antracnose na pós-colheita de mangas 'Ubá'.

\section{MATERIAL E MÉTODOS}

Mangas 'Ubá' fisiologicamente maduras foram obtidas no pomar experimental da Fazenda Sementeira, pertencente à Universidade Federal de Viçosa (UFV), localizada no município de Visconde do Rio Branco-MG, situado em $21^{\circ} 00^{\prime} 37^{\prime} \mathrm{S}, 42^{\circ}$ 50 ' 26 "'W, a uma altitude de $352 \mathrm{~m}$ em relação ao nível do mar, sendo o clima tipo Cwa, segundo classificação de Köppen.

Em seguida, foram transportadas até o Galpão de Pós-Colheita do Setor de Fruticultura do Departamento de Fitotecnia da UFV, em caixas forradas com plástico-bolha, e em camadas únicas para evitar ferimentos. Posteriormente, foi realizada a seleção de acordo com a ausência de injúrias e podridões, uniformidade de cor e tamanho. Após a seleção, os frutos foram lavados com detergente neutro a $2 \mathrm{~mL} / \mathrm{L}$ e enxaguados em água potável. Logo após, foram desinfestados em solução de hipoclorito de sódio a $0,5 \%(\mathrm{v} / \mathrm{v})$ durante três minutos, novamente enxaguados em água potável e colocados para secar ao ar.

Após esse processo, as mangas foram inoculadas com o fungo $C$. gloeosporioides através da pulverização de uma suspensão de conídios, na concentração de $2,5 \times 10^{5}$ conídios $/ \mathrm{mL}$, com o uso de pulverizador manual. Logo após a secagem da suspensão do inóculo, os frutos foram pulverizados até o completo molhamento, com um dos seguintes produtos: água destilada (testemunha), tween 20 (8 $\mathrm{mL} / \mathrm{L}$ de solução), Prochloraz (1,10 mL de Sportak $450 \mathrm{EC} / \mathrm{L}$ de solução), óleo de alho $(10 \mathrm{~mL} / \mathrm{L}+8$ $\mathrm{mL} / \mathrm{L}$ de tween 20 ), óleo de amêndoa de $A$. aculeata + leite em pó instantâneo (LPI) $(25 \mathrm{~mL} / \mathrm{L}+10 \mathrm{~g}$ LPI/L), óleo de amêndoa de $A$. aculeata + tween $(25 \mathrm{~mL} / \mathrm{L}+8 \mathrm{~mL} / \mathrm{L}$ de tween 20$)$, biofertilizante agro-mos ${ }^{\circledR}(100 \mu \mathrm{L} / \mathrm{L})$, óleo de neen $(10 \mathrm{~mL} / \mathrm{L}+8$ $\mathrm{mL} / \mathrm{L}$ de tween 20$)$, quitosana $(10 \mathrm{~mL} / \mathrm{L}+8 \mathrm{~mL} / \mathrm{L}$ de tween 20) e biomassa cítrica $(10 \mathrm{~mL} / \mathrm{L}+8 \mathrm{~mL} / \mathrm{L}$ tween 20). O solvente utilizado foi água destilada.

Utilizou-se leite em pó instantâneo como emulsificante natural. Este produto contém lecitina, que facilita a dissolução do óleo na água, além de ser um produto facilmente disponível.

Os frutos foram acondicionados em grupos de três, em bandejas de poliestireno expandido, e armazenados em câmara a $21^{\circ} \mathrm{C} \pm 1{ }^{\circ} \mathrm{C}$ e $90 \%$ UR, onde permaneceram por 14 dias, sendo avaliados a cada dois dias. O experimento foi conduzido em parcelas subdivididas no tempo, tendo-se nas parcelas os produtos testados (10 produtos), e nas subparcelas, os dias de avaliações $(0 ; 2 ; 4 ; 6 ; 8$; $10 ; 12$ e 14 dias). O delineamento experimental 
utilizado foi o inteiramente casualizado com dez repetições, e cada unidade experimental, constituída de três frutos. Avaliaram-se o período de incubação, período latente, perda de massa fresca (gravimetria), produção de $\mathrm{CO}_{2}$ e, diariamente, a severidade e a incidência da doença.

A produção de $\mathrm{CO}_{2}$ pelos frutos foi determinada a cada dois dias, sendo utilizadas quatro repetições para cada tratamento. As determinações foram feitas por cromatografia gasosa, utilizandose de um cromatógrafo a gás Gow Mac, série 550, equipado com detector de condutividade térmica. As condições de trabalho foram: fluxo de $40,0 \mathrm{~mL} / \mathrm{min}$ de gás hélio, que foi o gás de arraste; corrente elétrica de $150 \mathrm{~mA}$; temperaturas da coluna, do detector e do injetor de $50 ; 70$ e $80{ }^{\circ} \mathrm{C}$, respectivamente; e temperatura ambiente em torno de $25^{\circ} \mathrm{C}$.

$\mathrm{O}$ período de incubação compreendeu o intervalo entre a inoculação até o aparecimento dos primeiros sintomas (PARLEVLIET, 1975). Já o período latente compreendeu o período entre a inoculação e o aparecimento dos primeiros sinais do patógeno.

A severidade refere-se à proporção de área de tecido colonizado, e sua determinação foi feita com o auxílio de escala diagramática específica para a antracnose em mangas, variando de $0-1 \%$ (sem doença); 1 - 5\% (doença leve); 6 - 9\% (doença moderada); 10 - 49\% (doença severa), e 50-100\% de área lesionada/fruto (doença muito severa) (CORKIDI et al., 2006).

A incidência da doença foi calculada pelo número de frutos sintomáticos em cada tratamento, em que a \% Incidência $=\left(\mathrm{N}^{\mathrm{o}}\right.$ de frutos sintomáticos $/$ $\mathrm{N}^{\mathrm{o}}$ total de frutos) x 100 .

A partir dos dados de severidade e incidência da antracnose, calcularam-se os valores da Área Abaixo da Curva de Progresso da Doença (AACPD) para cada tratamento, conforme metodologia proposta por Shaner e Finney (1977).

Os dados foram submetidos à análise de regressão não linear e analisados com o auxílio do Sistema de Análises Estatísticas e Genéticas (SAEG, 2007). Para a análise de produção de $\mathrm{CO}_{2}$, a estatística foi descritiva, e para AACPD, teste de Tukey $(\mathrm{P}<0,05)$.

\section{RESULTADOS E DISCUSSÃO}

A incidência da doença ajustou-se a um modelo sigmoidal (Figura 1).

As respostas à incidência do inóculo de $C$. gloesporiodes em mangas tratadas com diferentes produtos alternativos e com fungicida, quanto a
AACPD, diferiram estatisticamente. Observou-se inicialmente menor AACPD (Figura 1A) nos frutos tratados com óleo de amêndoa de $A$. aculeata + LPI.

A partir do quarto dia após a inoculação, houve uma rápida ascensão da percentagem de frutos colonizados tratados com óleo de neen, biomassa cítrica e água + tween. Em frutos tratados com óleo de amêndoa de $A$. aculeata + LPI, agro-mos ${ }^{\circledR} \mathrm{e}$ água, a incidência da doença aumentou de forma mais gradual, atingindo seu máximo entre o sétimo e o oitavo dia após a inoculação. Frutos tratados com Prochloraz, quitosana, óleo de alho e óleo de amêndoa de $A$. aculeata + tween apresentaram a mesma tendência na percentagem de frutos colonizados, sendo maior no tratamento com óleo de amêndoa de $A$. aculeata + tween e menor com a quitosana. A partir do nono dia após a inoculação, a incidência atingiu $100 \%$ em todos os tratamentos (Figura 1).

Esses resultados confirmam a importância do controle da antracnose na pós-colheita de manga, visto que a simples presença dos sintomas desqualifica o fruto para a comercialização.

Carnelossi et al. (2009) relataram que os efeitos da biomassa cítrica não diferiram significativamente dos efeitos da testemunha com inoculação, quando trabalharam com o controle póscolheita de antracnose em mamão.

Sousa et al. (2012) avaliaram o efeito fungitóxico do óleo de neen sobre o desenvolvimento do fungo C. gloeosporioides, in vitro e em frutos de pimenta-de-cheiro (Capsicum chinense) em pós-colheita na concentração de $0,2 \% ; 0,4 \% ; 0,6 \%$; $0,8 \%$ e $1,0 \%$ adicionados ao meio de cultura BDA e constataram que a utilização do óleo, em todas as cinco concentrações utilizadas, obteve os melhores resultados quanto à inibição do crescimento do fungo, contradizendo com os resultados obtidos neste experimento.

Os valores de severidade da doença ajustaramse ao modelo sigmoidal em função dos dias de avaliação, para todos os produtos testados (Figura 2).

Houve diferença estatística quanto AACPD (Figura 2), e apenas os frutos tratados com fungicida apresentaram menor AACPD quando comparadas aos demais tratamentos.

Os frutos, de modo geral, apresentaram valores crescentes de severidade, os tratados com água, água + tween, agro-mos ${ }^{\circledR}$ e óleo de neen exibiram maior área colonizada pelo patógeno. $\mathrm{O}$ tratamento com Prochloraz não impediu a incidência de antracnose nos frutos, mas reduziu a severidade da doença em relação a todos os outros tratamentos. O óleo de amêndoa de $A$. aculeata + LPI e 
o Prochloraz foram os mais eficientes em conter a colonização do patógeno até o oitavo dia após a inoculação. Porém, logo em seguida, os frutos tratados com óleo de amêndoa de $A$. aculeata + LPI igualaram-se àqueles tratados com a maioria dos demais produtos. Os valores encontrados da área colonizada pelo fungo no tratamento com Prochloraz foi $39,06 \%$ e $36,86 \%$ menor em relação ao agromos ${ }^{\circledR}$ e à água, respectivamente (Figura 2).

No oitavo dia após a inoculação, apenas o Prochloraz se destacou no controle da doença (Figura 2), retardando o aumento da severidade em $56,26 \%$ e, no último dia de avaliação, em relação à média dos demais produtos.

Lima et al. (2008), avaliando o efeito de produtos naturais no controle de antracnose em manga 'Ômega', observaram que o óleo de amêndoa de A. aculeata + LPI foi o melhor tratamento em relação à severidade e à área necrosada.

Quanto ao período de incubação, com exceção dos tratamentos com óleo de amêndoa de A. aculeata + LPI e o Prochloraz que apresentaram os primeiros sintomas no quinto dia, os demais tratamentos avaliados apresentaram os sintomas da doença no quarto dia. No entanto, foram observadas diferenças na intensidade com que a doença afetava $o$ fruto.

Em relação ao período latente, os frutos tratados com biomassa cítrica, quitosana, óleo de alho, agro-mos ${ }^{\circledR}$, água e água + tween apresentaram o sinal da doença nos dias 12,5;12,7; 12,1; 12,4; 12,6 e 12,5 dias após a inoculação, respectivamente. Nos frutos tratados com óleo de amêndoa de $A$. aculeata + LPI e óleo de amêndoa de A. aculeata + tween, as estruturas do patógeno tornaram-se visíveis apenas nos dias 13 e 14 de avaliação, sugerindo efeito inibitório de seus princípios ativos sobre as estruturas do patógeno. Os frutos tratados com Prochloraz não apresentaram sinal da doença no período avaliado. Do ponto de vista da pós-colheita, quanto maior for o tempo para o aparecimento de estruturas do patógeno, menores serão as chances de um fruto colonizado contaminar um fruto sadio.

Os valores de perda de massa da matéria fresca ajustaram-se a um modelo linear crescente em função dos dias de avaliação, para todos os produtos (Figura 3).

Os maiores valores de perda de massa da matéria fresca (PMMF) foram observados nos frutos tratados com óleo de alho e biomassa cítrica, com $8,31 \%$ e $8,44 \%$, no dia 14 , respectivamente e, logo em seguida, situaram-se os frutos do tratamento com Prochloraz (Figura 3).

Após a inoculação, durante todo o período de avaliação, as mangas pulverizadas com óleo de amêndoa de $A$. aculeata + LPI e óleo de neen foram as que apresentaram menor perda de matéria fresca em relação a todos os outros tratamentos, sendo $6,34 \%$ e $6,37 \%$, respectivamente. No entanto, esses resultados referentes à perda de umidade pelos frutos já são considerados níveis que causam enrugamento e murchamento das mangas, o que compromete o aspecto visual e reduze seu valor comercial (CHITARRA; CHITARRA, 2005).

Os frutos, até o segundo dia após a inoculação, apresentaram taxas respiratórias reduzidas. A partir daí, observou-se elevação na produção de $\mathrm{CO}_{2}$, com exceção do óleo de amêndoa de $A$. aculeata + LPI e óleo de amêndoa de $A$. aculeata + tween, que mantiveram a taxa respiratória crescente até o dia 12. Esse comportamento pode ser explicado pela formação de uma camada protetora que, provavelmente, formou-se devido à maior concentração de óleo utilizada no tratamento com óleo de amêndoa de $A$. aculeata em relação aos outros tratamentos. No dia 14 , ocorreu redução na respiração (Figura 4).

Os frutos tratados com água, água + tween apresentaram o pico climatérico da respiração no quarto dia de avaliação, e naqueles tratados com os demais produtos, o pico ocorreu no oitavo dia após os tratamentos (Figura 4).

Após o pico respiratório, houve declínio da produção de $\mathrm{CO}_{2}$ (pós-climatérico), tornando a elevar-se entre 12 e 14 dias após a inoculação para os frutos tratados com óleo de neen, quitosana, óleo de alho, agro-mos ${ }^{\circledR}$, água, água + tween e Prochloraz. (Figura 4). Nesses, o aumento da severidade e, consequentemente, da área da casca lesionada pela doença, verificada a partir do dia 12 após os tratamentos, elevou a produção de etileno, o que explica a retomada da elevação na produção de $\mathrm{CO}_{2}$. A respiração do próprio fungo também deve ter contribuído para esse aumento final da produção de $\mathrm{CO}_{2}$ (MARENCO; LOPES, 2007).

De acordo com os resultados encontrados, há ainda necessidade de estudos mais detalhados com os produtos no que se refere ao modo de aplicação, tempo de imersão dos frutos, concentração, $\mathrm{pH}$ e temperatura da calda, possibilidade da utilização destes produtos como sanitizantes, dentre outros, devendo ser esses produtos testados em condições comerciais. 


\begin{tabular}{|c|c|c|c|}
\hline & & $\left.p\left(10,75954-2,70057^{* *} D 1\right)\right)$ & \\
\hline & $\begin{array}{l}\text { Biomassa Cítrica } \\
\text { Óleo de Neen }\end{array}$ & $\hat{Y}=98,66886 /\left(1+\exp \left(28,18329-7,46873^{* *} D\right)\right)$ & $\mathrm{R}^{2}=0,997$ \\
\hline-- & Quito & $\hat{Y}=99,03273 /\left(1+\exp \left(5,72382-1,30283^{* *} D\right)\right)$ & $\mathrm{R}^{2}=0,984$ \\
\hline$-\Delta$ & Óleo de Alho & $\hat{Y}=99,61027 /\left(1+\exp \left(5,38804-1,21977^{* *} D\right)\right)$ & $\mathrm{R}^{2}=0,97$ \\
\hline- & Agro-Mos & $\hat{Y}=100,3181 /\left(1+\exp \left(4,99649-1,0271^{* *} D\right)\right)$ & \\
\hline & $\mathrm{a}+\mathrm{LPI}$ & $\hat{Y}=101,58591 /\left(1+\exp \left(5,83202-0,98997^{* *} D\right)\right)$ & $\mathrm{R}^{2}=0$ \\
\hline$\rightarrow$ & Água destilada & $\hat{Y}=100,75027 /\left(1+\exp \left(5,43485-1,03825^{* *} D\right)\right)$ & $\mathrm{R}^{2}=0,99$ \\
\hline & estilada + twe & $\hat{Y}=98,00281 /\left(1+\exp \left(27,56956-7,32626^{* *} D\right)\right)$ & $\mathrm{R}^{2}=0,99$ \\
\hline & & $\begin{array}{l}\hat{Y}=100,42219 /\left(1+\exp \left(6,09839-1,36769^{* *} D\right)\right) \\
\hat{Y}=99,8482 /\left(1+\exp \left(6,10257-1,42336^{* *} D\right)\right)\end{array}$ & \\
\hline
\end{tabular}
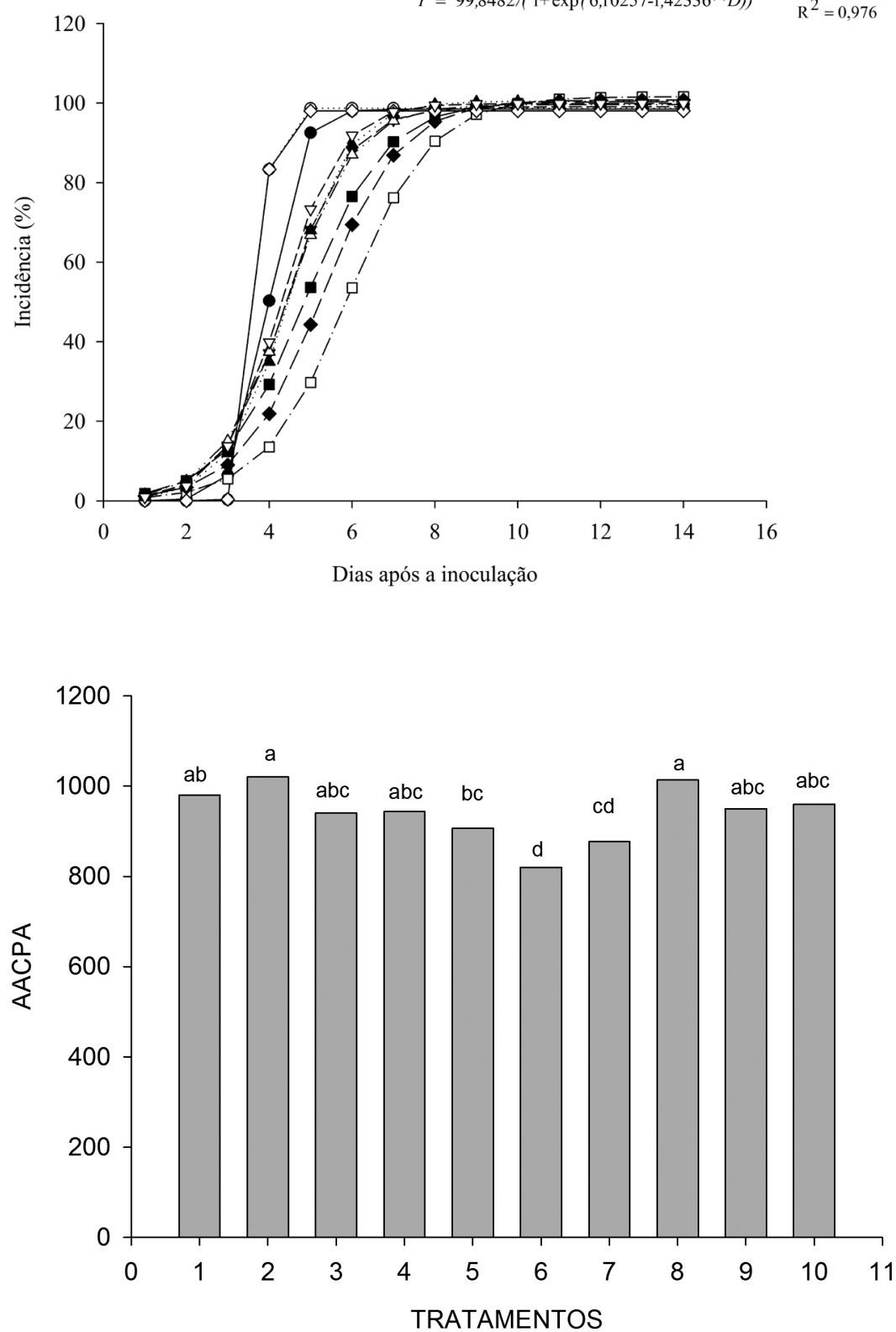

FIGURA 1- Curvas de progresso de incidência da antracnose (A), e a área abaixo da curva de progresso da doença (AACPD) (B) em mangas 'Ubá' inoculadas Colletotrichum gloeosporioides, tratadas com fungicida e diferentes produtos alternativos aos agroquímicos, e armazenadas a $21 \pm 1^{\circ} \mathrm{C}$ e $90 \%$ de UR por 14 dias (D).

Médias seguidas pela mesma letra não diferem entre si, pelo teste de Tukey, ao nível de 5\% de probabilidade. 

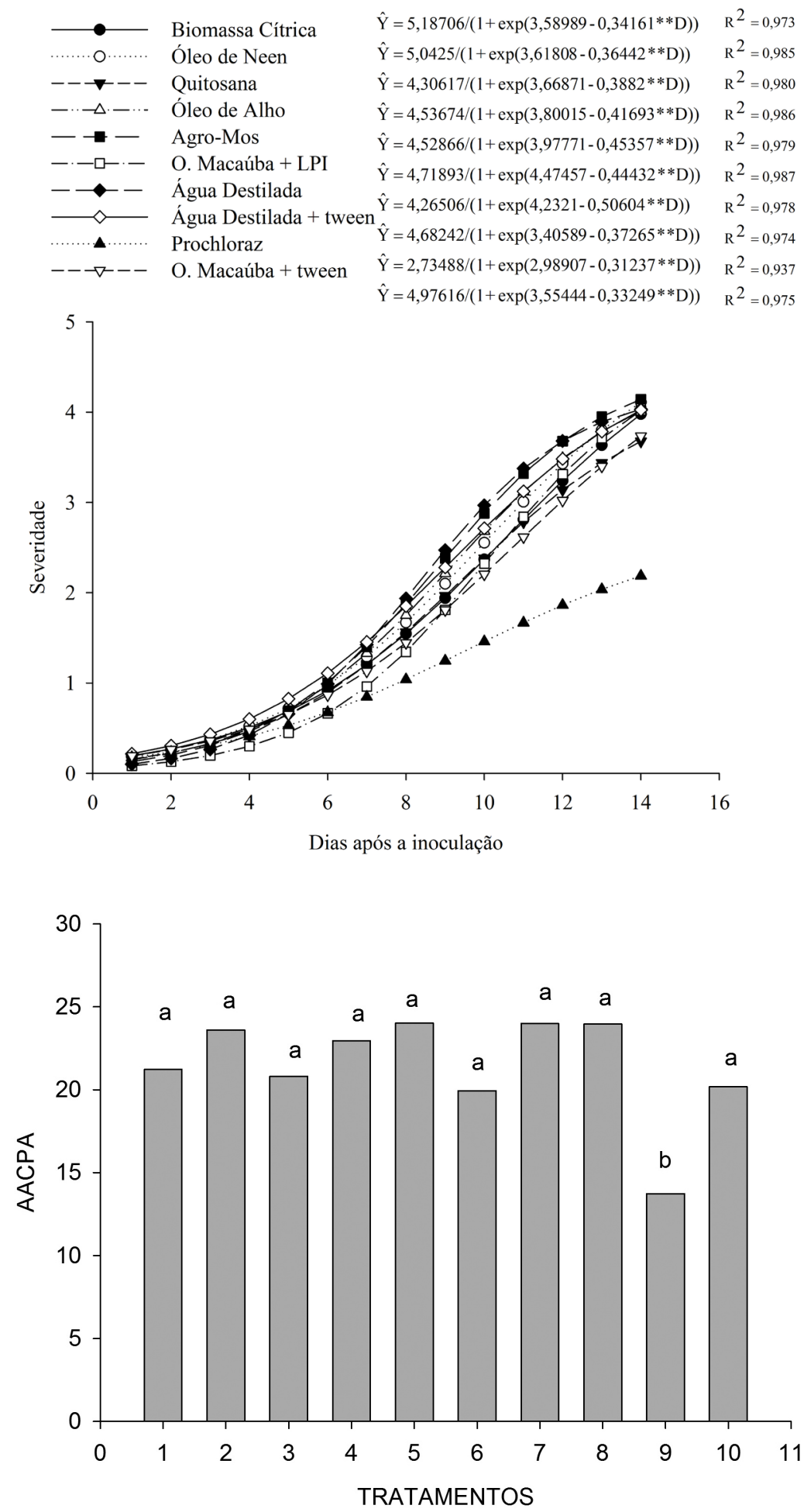

FIGURA 2 - Curvas de progresso de severidade da antracnose (A), e a área abaixo da curva de progresso da doença (AACPD) (B) em mangas 'Ubá' inoculadas Colletotrichum gloeosporioides, tratadas com fungicida e diferentes produtos alternativos aos agroquímicos, e armazenadas a $21 \pm 1{ }^{\circ} \mathrm{C}$ e $90 \%$ de UR por 14 dias (D).

Médias seguidas pela mesma letra não diferem entre si, pelo teste de Tukey, ao nível de $5 \%$ de probabilidade. 


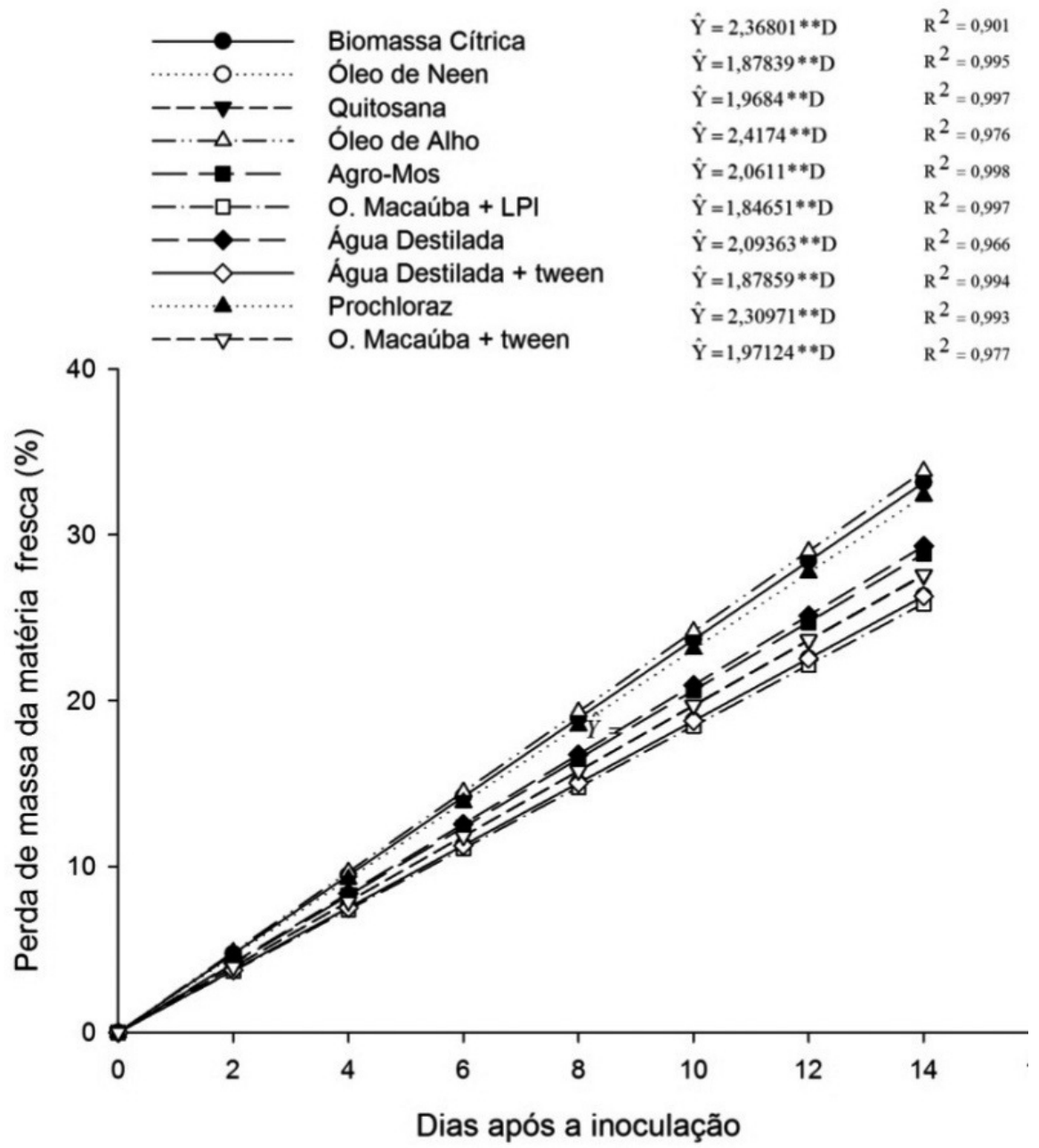

FIGURA 3- Estimativa da perda de massa da matéria fresca em mangas 'Ubá' inoculadas com Colletotrichum gloeosporioides, tratadas com fungicida e diferentes produtos alternativos aos agroquímicos e armazenadas a $21 \pm 1{ }^{\circ} \mathrm{C}$ e $90 \%$ de UR por 14 dias (D). 


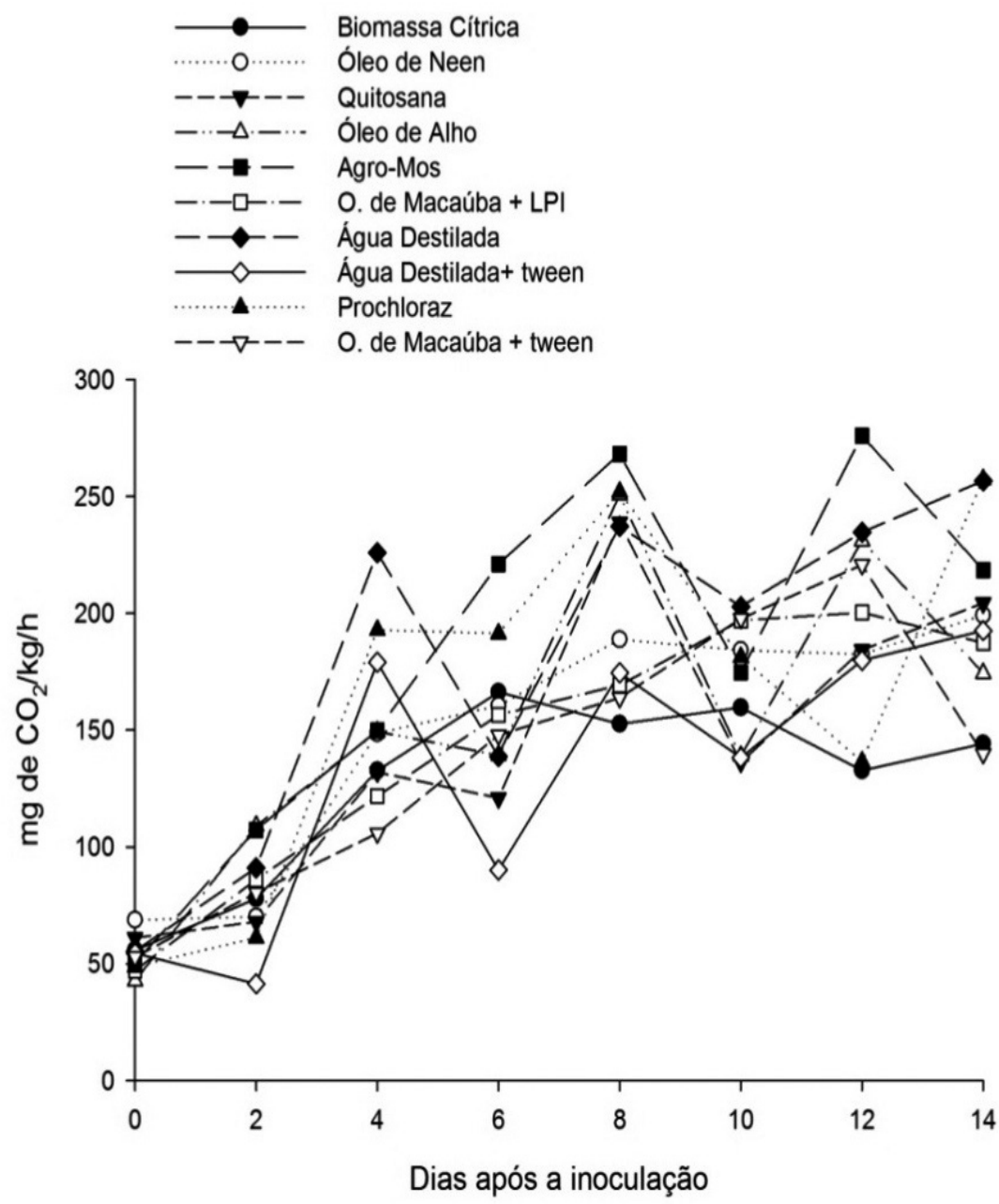

FIGURA 4-Taxa respiratória ( $\mathrm{mg}$ de $\mathrm{CO}_{2} / \mathrm{kg} / \mathrm{h}$ ) de mangas 'Ubá' inoculadas com Colletotrichum gloeosporioides, tratadas com fungicida e diferentes produtos alternativos aos agroquímicos e armazenadas a $21 \pm 1{ }^{\circ} \mathrm{C}$ e $90 \%$ de UR por 14 dias (D).

\section{CONCLUSÃO}

Dentre os produtos alternativos testados, óleo de amêndoa de Acrocomia aculeata, tanto com tween como com o LPI, é o que se mostra mais efetivo no controle do agente da antracnose em mangas 'Ubá', enquanto o agro-mos® é o menos efetivo.

\section{AGRADECIMENTO}

Ao Conselho Nacional de Desenvolvimento Científico e Tecnológico (CNPq), pelo apoio financeiro à condução deste trabalho.

\section{REFERÊNCIAS}

ABREU, F. M.; LOURENÇO, S. A.; BASSETTO, E.; GONÇALVES, F. P.; MARTINS, M. C.; AMORIM, L. Efeito de sanificantes no controle póscolheita da podridão-parda (Monilinia fructicola) e da podridão-mole (Rhizopus stolonifer) em pêssegos. Summa Phytopathologica, Botucatu, v. 34, n. 1, p. 83-85, 2008.

BAGSHAW, J. Mango pest and disorders. Queensland: Departament of Primary Industries, 1989. p. 44. 
BAUTISTA-BANÕS, S.; HERNANDEZLAUZARDO, A. N.; VELAZQUEZ-DEL VALLE, M. G.; HERNÁNDEZ-LOPEZ, M.; BARKA, E. A.; BOSQUEZ-MOLINA, E.; WILSON, C. L. Chitosan as a potencial natural compound to control pre and postharvest diseases of horticultural commodities. Crop Protection, Amsterdam, v.25, n. 2. p.108118, 2006.

CAMILI, E. C.; BENATO, E. A.; PASCHOLATI, S. F.; CIA, P. Avaliação da quitosana, aplicada em póscolheita, na proteção de uva 'Itália' contra Botrytis cinerea. Summa Phytopathologica, Botucatu, v. 33, n. 3, p 215-221, 2007.

CARNELOSSI, P. R.; SCHWAN-ESTRADA, K. R. F.; CRUZ, M. E. S.; ITAKO, A. T.; MESQUINI, R. M. Óleos essenciais no controle pós-colheita de Colletotrichum gloeosporioides em mamão. Revista Brasileira de Plantas Medicinais, Botucatu, v.11, n.4, p.399-406, 2009.

CHITARRA, M. I. F.; CHITARRA, A. B. Póscolheita de frutos e hortaliças: fisiologia e manuseio. 2. ed. Lavras: UFLA, p. 785, 2005.

CORKIDI, G.; BALDERAS-RUÍZ, K. A.; TABOADA, B.; SERRANO-CARREÓN, L.; GALINDO, E. Assessing mango anthracnose using a new three-dimensional image-analysis technique to quantify lesions on fruit. Plant Pathology, Cuernavaca, v. 55, p. 250-257, 2006.

FIORI, A. C. G.; SCHWAN-ESTRADA, K. R. F.; STANGARLIN, J. R.; VIDA, J. B.; SCAPIM, C. A.; CRUZ, M. E. S.; PASCHOLATI, S. F. Antifungal activity of leaf extracts and essencial oils of some medicinal plants against Didymella bryoniae. Journal of Phytopathology, Weinheim, v. 148, p. 483-487, 2000.

LIMA, C. A. de; JUNQUEIRA, N. T. V.; SOUZA, L. S. de; SILVA, D. G. P. da; JUNQUEIRA, K. P.; SANTOS, E. C. dos. Efeito de produtos naturais no controle de antracnose na manga em póscolheita. In: SIMPÓSIO NACIONAL CERRADO, 9.; SIMPÓSIO INTERNACIONAL SAVANAS TROPICAIS, 2., 2008, Brasília. Anais...
MARENCO, R. A.; LOPES, N. F. Fisiologia vegetal: fotossíntese, respiração, relações hídricas e nutrição mineral. 2. ed. rev. ampl. Viçosa: Editora UFV, 2007. p. 469

MOSSINI, S. A. G.; KEMMELMEIER, C. A árvore Nim (Azadirachta indica A. Juss): Múltiplos Usos. Acta Farmacêutica Bonaerense, Maringá, v. 24, n. 1, p. 139-48, 2005

NOGUEIRA, D. R. S.; ALBUQUERQUE, L. B.; ARAÚJO, J. A. de M.; VALE, E. V. G.; SALES JÚNIOR, R. Eficiência de Bacillus subtilis e B. pumilus no controle de Podosphaera xanthii em meloeiro. Revista Verde de Agroecologia e Desenvolvimento Sustentável, Mossoró, v. 6, n.3, p. 125-130, 2011.

PARLEVLIET, J. E. Partial resistance of barley of leaf rust. Puccinia hordei I. Effect of cultivar and development stage on latent period. Euphytica, Wageningen, v. 24: n.1, p. 21-27, 1975.

ROSA, R. C. T. da; CAVALCANTI, V. A. L. B; COELHO, R. S. B.; PAIVA, J. do E. de. Efeito de produtos alternativos e de fungicidas no controle do míldio da videira. Summa Phytopathologica, Botucatu, v.34, n.3, p. 256-258, 2008.

ROZWALKA, L. C.; LIMA, M. L. R. Z. C.; MIO, M. L.L.; NAKASHIMA, T. Extratos, decoctos e óleos essenciais de plantas medicinais e aromáticas na inibição de Glomerella cingulata e Colletotrichum gloeosporioides de frutos de goiaba. Ciência Rural, Santa Maria, v. 38, n. 2, p. 301-307, 2008.

SAEG. Sistema para análise estatística. Versão 9.1. Viçosa: Fundação Arthur Bernades, 2007.

SHANER, G.; FINNEY, R.E. The effect of nitrogen fertilization on the expression of slow mildewing resistance in Knox wheat. Phytopathology, Saint Paul, v.67, p.1051-1056, 1977.

SOUSA, R. M.S.; SERRA, I. M. R. S.; MELO, T. A. Efeito de óleos essenciais como alternativa no controle de Colletotrichum gloeosporioides, em pimenta. Summa Phytopathologica, Botucatu, v.38, n.1, p.42-47, 2012. 